\title{
A comparison of slamming impact models on orthotropic sandwich panels
}

\author{
J. Walsh ${ }^{1}$, G. Hou ${ }^{2}$ \& K. Soman ${ }^{2}$ \\ ${ }^{1}$ United States Navy, USA \\ ${ }^{2}$ Department of Mechanical Engineering, Old Dominion University, \\ Virginia, USA
}

\begin{abstract}
Hull slamming due to wave impacts is a challenging problem in the design of high-performance, sandwich-construction marine craft. Sandwich composites have mechanical properties fundamentally different from those of steel or aluminum, and sandwich core shear is a common failure mode in planing craft hull panels. This paper compares the slamming response of an isotropic hull panel with an orthotropic composite sandwich panel. Linear, 3D finite element analysis is performed for a spatially constant pulse model and a traveling pulse model. It is shown that sandwich panel response is sensitive to pressure variation in both time and space. Therefore, dynamic analysis of a traveling pulse is essential for effective design.
\end{abstract}

Keywords: slamming, composite, sandwich panel, wave impact, pressure pulse, core shear, orthotropic, finite element analysis, natural frequency.

\section{Introduction}

Hull slamming due to wave impacts is a challenging problem in the design of high-performance marine craft. It is common to state the hull stress response of a slamming impact in terms of an equivalent uniform static load or as a spatially constant dynamic pressure pulse. This has been useful for isotropic materials, which fail in tension at the fixed panel edges. Sandwich composites have mechanical properties fundamentally different from those of steel or aluminum, and sandwich core shear is a common failure mode in planing craft hull panels.

Slamming can be defined as a severe impulsive hydrodynamic load with a short time constant relative to the periods associated with ship motions or 
buoyant wave loads. The slamming event may excite the lower structural modes of the hull girder and abruptly change the vessel's rigid-body motion (Lewis et al [1]). Vessels operating at high speeds may encounter severe wave impacts that can damage the hull (Grimsley [2]). Slamming pressures of $\sim 700 \mathrm{kPa}$ have been recorded (Battley and Lake [3]), but higher pressures are possible.

This paper compares the slamming response of an isotropic hull panel with an orthotropic composite sandwich panel. Linear, 3D finite element analysis is performed on a square grid with fixed boundary conditions. The results are compared for a spatially constant pulse model and a traveling pulse model. Sandwich panel response is sensitive to pressure variation in both time and space, so sandwich hulls require a traveling pulse analysis instead of the spatially constant approximation used for isotropic hulls.

\section{Existing approaches}

Slamming pressures act normal to the hull panel surface and may be separated into two components: the impact pressure due to the normal component of the relative velocity between the panel and the wave, and the planing pressure due to the tangential component. The planing pressure is usually insignificant compared to the impact pressure. Using the results of drop testing, Stavovy and Chuang [4] developed a formula to predict the peak impact pressure of any slamming event as a function of normal velocity, fluid density, and effective impact angle, which itself is a function of trim, deadrise, and wave slope.

\subsection{Quasi-static approximation}

While slamming data have been recorded for a number of craft under varying sea states, it is difficult to reproduce particular conditions reliably at sea because each slamming impact is a unique event (Downs-Honey et al [5]). Because of the random nature of impact loading, designers have traditionally neglected a dynamic load prediction. They favored designs based on a quasi-static uniform pressure load intended to mimic the hull panel stresses from the maximum impact load the vessel might encounter [2]. After all, the design engineer is concerned with the actual slamming pressure only to the extent that the event causes a structural response. Pressures that are localized in space or have very short duration may produce very little response at all. It is not the peak amplitude that matters but the integrated pressure over a much larger area and span of time. The dominant response depends more on the stiffener and frame spacing than the actual peak pressure [1].

\subsection{Spatially constant pulse approximation}

Advances in computing power have enabled highly detailed analysis of hull forms and correlation of experimental wave impact data. It is possible to predict the maximum slamming pressure on any hull panel over the vessel's lifetime, based on the expected environmental and service conditions of the craft (Garme and Rosén, [6]). Shipbuilders can perform economical dynamic predictions of 
slamming pulse effects on hull panels. In such analyses, it is a common and reasonable simplifying approximation that the slamming pressure varies in time but not in space, i.e. that a pulse acts on the entire panel at once rather than traveling across it from keel to chine (Allen and Jones [7]). If that assumption is reasonable then finite element analysis can take advantage of symmetry to save time and cost. The assumption also removes pulse front velocity as a variable, which otherwise makes the analysis less general and more complex. Henke [8] justified this approximation by comparing the plate response to both a traveling pulse and a spatially constant pulse with the same time decay and peak magnitude. In doing so, he used the following assumptions:

\subsubsection{Boundary conditions}

Hull panels are rectangular and isotropic. During a slamming event, adjacent plates are subjected to the impact load, so there is mutual resistance to edge pullin. Therefore, fixed boundary conditions apply, and the maximum stress occurs at the midpoint of the long edge of the panel.

\subsubsection{Strip theory}

The panel is oriented with the long edge parallel to the keel, and the aspect ratio is greater than 2. The pulse pressure profile is constant in the direction of the panel parallel to the keel. Therefore, symmetry and 1D plate strip theory can be used in place of a full 2D analysis to reduce the computational cost.

\subsubsection{Pulse shape}

Slamming pressure at any point on the panel shows a sharp initial rise and a gradual exponential decay in time as the pressure pulse propagates outward. The peak pressure is constant as the pulse front traverses the panel from keel to chine. During real-world slamming events, the pulse magnitude reduces due to the decreasing downward velocity of the ship. However, the width of the panel under consideration is a fraction of the distance that the pulse front travels; hence, the reduction in peak pressure is negligible.

\subsubsection{Decay constants}

Time decay is constant as the pulse front traverses the panel. Based on experiments with a wedge-shaped hull, the time decay stays constant for a given traveling pulse, even though the pulse magnitude reduces. Just as a pulse has a decay constant in time when referenced at a point in space, it has an associated decay constant in space when referenced at a particular instant in time. Henke characterized the spatial variation of pressure across the panel with a spatial decay constant:

$$
\mathrm{X}_{\mathrm{s}}=\tau \mathrm{c}_{\mathrm{p}}
$$

where $\tau$ is the time decay constant in seconds and $c_{p}$ is the pulse front velocity. $\mathrm{X}_{\mathrm{s}}$ is equivalent to the distance that a pulse front travels in the time it takes for the pressure at any point to decay by $\sim 63 \%$. 


\subsection{Henke's criterion for rectangular isotropic plates}

Henke compared several 1D strip theory finite element analyses with varying pulse front velocities to a spatially constant pulse that varied only in time (equivalent to an infinite pulse front velocity). Henke showed that it is reasonable to approximate a traveling pressure pulse as spatially constant, varying only in time, if the dimensionless spatial decay constant $\mathrm{X}_{\mathrm{s}} / \mathrm{L}$ is greater than one (where $\mathrm{L}$ is the length of the panel from keel to chine). The error in peak stress was within $7 \%$ for all $\mathrm{X}_{\mathrm{s}} / \mathrm{L} \geq 1$, and reduced as $\mathrm{X}_{\mathrm{s}} / \mathrm{L}$ increased. Therefore, $X_{s} / L \geq 1$ is a condition for acceptable accuracy of the spatially constant pulse approximation for rectangular, isotropic panels. Henke further stated, "This is quite reasonable since actual slamming conditions show $\mathrm{X}_{\mathrm{s}} / \mathrm{L}$ ratios greater than one as indicated by records of pulse front velocities [8]."

Henke also found a correlation between pulse frequency content and the natural frequency of an isotropic panel [8]. He showed that the peak response of an isotropic hull panel generally occurs in a narrow band of pulse time decay constants, near the reciprocal of the natural frequency $\mathrm{F}_{0}$.

\section{Current study}

Before conducting a similar analysis on a square isotropic panel and an equivalent orthotropic sandwich panel, the time-domain shape of a pressure pulse is examined. An idealized slamming pulse starts with a rapid pressure peak that moves from the keel line toward the chine of the hull. The pressure peak is characterized by a very short rise time, and an exponential decay defined by the time decay constant $\beta$, in $\sec ^{-1}$, such that:

$$
\beta=1 / \tau
$$

$\beta$ and $P_{\text {peak }}$ increase as impact velocity $V_{n}$ increases and impact angle $\xi$ decreases (Battley et al [9]). Because $\mathrm{V}_{\mathrm{n}}$ is assumed constant after water entry, a residual pressure remains after the peak pressure decays (Battley and Stenius [10]). Although this idealized pulse realistically describes actual observed slamming pulses, a simplified pulse shape based on work by Battley and Svensson [11] is chosen here for ease of computation.

\subsection{Simplified pulse shape}

The simplified pulse shape has a linear rise from zero to $\mathrm{P}_{\text {peak }}$ and a linear drop from $P_{\text {peak }}$ to a steady residual pressure. Finite element analysis shows that the maximum stress and panel deflection agree within $1 \%$ for the two different pulse shapes. Figure 1 is a comparison of the two pulse shapes with a value of $\beta=F_{0}$ $=369 \mathrm{sec}^{-1}$.

The relationship between the simplified and idealized pulse shapes is described entirely by the constant $\beta$, such that the fall slope from $P_{\text {peak }}$ to $P_{\text {residual }}$ in the simplified pulse is identical to the initial fall slope defined by $\beta$ for the 
idealized pulse. The linear rise slope is fixed at $4 \mathrm{x}$ the linear fall slope, based on inspection of real world slamming pulse traces. The pulse shapes match closely in the time period immediately preceding the maximum panel response, so the simplified pulse shape is acceptable for transient response analysis in this work. The maximum response for a spatially constant pulse occurs when the decay constant $\beta$ approximately equals the natural frequency $\mathrm{F}_{0}$, as Henke asserted [8].

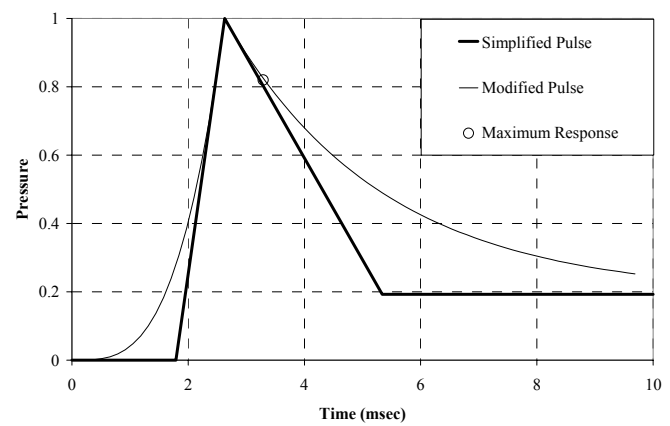

Figure 1: Comparison of idealized and simplified pulse shapes.

A real-world slamming pulse varies in space as well as in time, traveling from keel to chine as the hull impacts the water surface. For a given slamming event, the pulse front velocity $c_{p}$ can be calculated from the impact geometry:

$$
\mathrm{c}_{\mathrm{p}}=\mathrm{V}_{\mathrm{n}} / \sin \xi
$$

where $\xi \geq 2.2^{\circ}$ is the effective impact angle. Smaller angles are not considered because entrapped air cushions the impact and disrupts the pulse front, significantly reducing the slamming effect [4]. Although $\mathrm{P}_{\text {peak }}$ and $\beta$ also vary with the impact geometry, they were held constant for this study in order to isolate the effects of pulse front velocity.

\subsection{Isotropic panel analysis}

Transient analysis was conducted on a fixed, symmetric 3D panel grid (Figure 2), split in the $y z$ plane along the vertical centerline to take advantage of symmetry. The simplified pulse shape was used with $\beta=\mathrm{F}_{0}=369 \mathrm{sec}^{-1}$. Pulse travel was simulated such that the pressure started to rise first at the bottom row of elements then moved upward at pulse front velocity $c_{p}$. The pulse pressure profile was constant along the $x$ direction at any particular instant in time. The rise slope, $\mathrm{P}_{\text {peak }}$, fall slope, and $\mathrm{P}_{\text {residual }}$ values were identical at every element on the pressure side of the panel.

The spatially constant pulse model described above is like a traveling pulse with infinite velocity, so that the pulse acts on the entire panel at once. Therefore, a fast-moving pulse should cause a panel response similar to a spatially constant pulse [8]. 

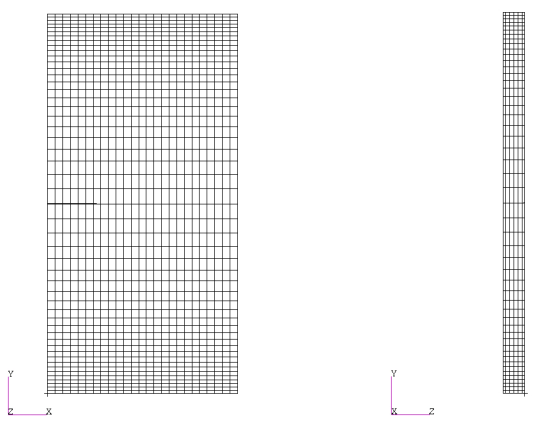

Figure 2: $\quad 3 \mathrm{D}$ grid for finite element analysis.

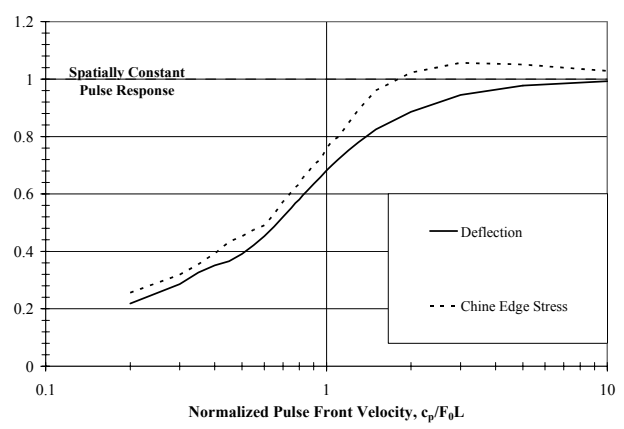

Figure 3: Slamming response of a square isotropic panel.

\subsection{Isotropic panel response}

Figure 3 shows the effect of changing pulse front velocity. The vertical axis is normalized to the spatially constant pulse response. The horizontal axis is normalized to $\mathrm{c}_{\mathrm{p}} / \mathrm{F}_{0} \mathrm{~L}$, which corresponds to Henke's dimensionless spatial decay constant $\mathrm{X}_{\mathrm{s}} / \mathrm{L}$. Maximum panel deflection and maximum stress are plotted. The results are similar to Henke's findings; a high pulse front velocity $c_{p}$ creates a panel response very close to that of a spatially constant pulse. However, the difference in the square panel chine edge stress is $24 \%$ at $\mathrm{c}_{\mathrm{p}} / \mathrm{F}_{0} \mathrm{~L}=1$, compared to Henke's $7 \%$ for the rectangular panel.

\subsection{Sandwich panel analysis}

The static and spatially constant dynamic methods successfully predict tensile stress in isotropic materials, which are dominated by bending stresses and deformation [3]. Shear stress is taken up gradually through the thickness of the panel, so it is a minor concern. However, those methods underestimate the shear effects of sandwich panel bending in which the core material carries essentially 
the entire shear load. As a result, core shear is a common failure mode in sandwich hulls subject to slamming loads. Experience shows that the assumptions used for isotropic hulls should not be applied blindly to sandwich panels because the materials respond differently to slamming impacts.

\subsubsection{Sandwich panel architecture}

The sandwich composite selected in this work for slamming analysis has E-glass skins and an orthotropic core manufactured under the TYCOR $®$ brand. The core is made of low-density plastic foam strips wound with helical E-glass rovings in a $\pm \theta$ angle pattern. The foam strips are consolidated into a board preform using hot-melt scrim cloth. The preform board is laminated with facing reinforcement (Figure 4) and infused with resin to form composite webs anchored to the two face sheets. The result is a lightweight core construction with high specific strength and stiffness and an excellent skin-to-core bond that resists delamination (Stoll et al [12]). The uni-directional composite architecture provides highly orthotropic core shear properties. The shear strength and stiffness are high in the direction of the webs and much lower perpendicular to the webs. For TYCOR $\mathbb{R}$ panels under a distributed normal load, the limiting failure mode is core shear perpendicular to the webs. Table 1 summarizes the material properties.

\subsubsection{Sandwich panel response}

The TYCOR ${ }^{\circledR}$ G18 panel was analyzed using the same $3 \mathrm{D}$ grid used in Section 3.2 under the same loading conditions. The core webbing was oriented parallel to the $x z$ plane. The results are shown in Figure 5.

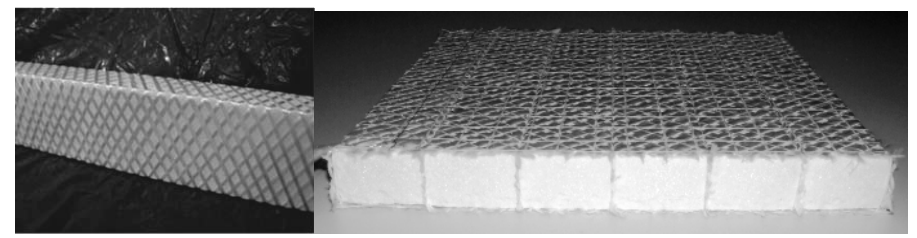

Figure 4: $\quad$ TYCOR ${ }^{\circledR}$ G18 panel architecture. (Reprinted with permission from WebCore Technologies, Miamisburg, Ohio.)

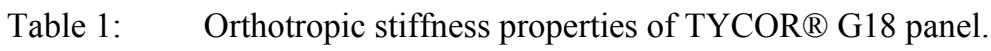

\begin{tabular}{|l|c|l|l|l|}
\hline \multicolumn{1}{|c|}{ Material } & $\begin{array}{c}\text { Thickness } \\
(\mathrm{cm})\end{array}$ & $\begin{array}{c}\text { Young's Modulus } \\
(\mathrm{MPa})\end{array}$ & \multicolumn{1}{c|}{$\begin{array}{c}\text { Shear Modulus } \\
(\mathrm{MPa})\end{array}$} & \multicolumn{1}{c|}{$\begin{array}{c}\text { Poisson } \\
\text { Ratio }\end{array}$} \\
\hline G18 core in & \multirow{2}{*}{2.54} & $\mathrm{E}_{\mathrm{L}} 338.3$ & $\mathrm{G}_{\mathrm{LT}} 1.92$ & $\mathrm{v}_{\mathrm{LT}} 0.28$ \\
vinylester resin & & $\mathrm{E}_{\mathrm{T}} 8.239$ & $\mathrm{G}_{\mathrm{TZ}} 2.76$ & $\mathrm{v}_{\mathrm{TZ}} 0.007$ \\
& & $\mathrm{E}_{\mathrm{Z}} 338.3$ & $\mathrm{G}_{\mathrm{LZ}} 200$ & $\mathrm{v}_{\mathrm{LZ}} 0.47$ \\
\hline 6 layers E-glass & \multirow{2}{*}{0.3825} & $\mathrm{E}_{\mathrm{L}} 25063$ & $\mathrm{G}_{\mathrm{LT}} 3564$ & $\mathrm{v}_{\mathrm{LT}} 0.135$ \\
roving in & per skin & $\mathrm{E}_{\mathrm{T}} 25063$ & $\mathrm{G}_{\mathrm{TZ}} 1328$ & $\mathrm{v}_{\mathrm{TZ}} 0.35$ \\
vinylester resin & & $\mathrm{E}_{\mathrm{Z}} 3585$ & $\mathrm{G}_{\mathrm{LZ}} 1328$ & $\mathrm{v}_{\mathrm{LZ}} 0.35$ \\
\hline
\end{tabular}




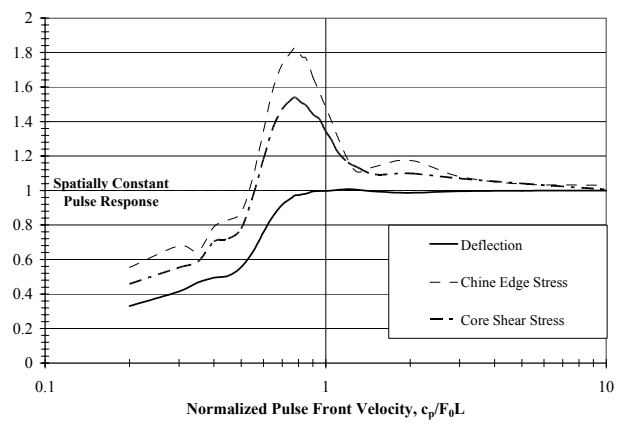

Figure 5: $\quad$ Slamming response of a square orthotropic sandwich panel.

The panel deflection, chine edge stress, and core shear stress converge very tightly for normalized pulse front velocity $c /\left(\mathrm{F}_{0} \mathrm{~L}\right)>1$. However, the orthotropic panel behaves very differently for a slower moving pulse with $\mathrm{c}_{\mathrm{p}}=$ $\beta \mathrm{L}=\mathrm{F}_{0} \mathrm{~L}$, which corresponds to Henke's criterion of $\mathrm{X}_{\mathrm{s}} / \mathrm{L}=1$ [8]. When the traveling pulse reaches the fixed boundary at the chine edge, a whipping effect leads to rapid peaks in core shear stress and chine edge stress, significantly higher than the stresses created by the spatially constant pressure pulse.

\section{Results and discussion}

Because of the highly orthotropic properties of the TYCOR ${ }^{\circledR}$ G18 panel, the first several harmonic mode shapes are symmetric about the vertical centerline of the panel. The inflectional variation of the panel response in the middle range of normalized pulse front velocities is created by reinforcement and cancellation of the panel's lower harmonic mode shapes. The maximum stresses occur for the pulse front velocity of $c_{p}=0.775 \mathrm{~F}_{0} \mathrm{~L}$. The first three mode shapes combine here to cause a maximum core shear stress $54 \%$ greater than that of the spatially constant pulse case, and a maximum chine edge stress $83 \%$ higher. The results show that Henke's [8] criterion for isotropic panel stress does not translate well for the TYCOR ${ }^{\circledR}$ G18 orthotropic sandwich panel.

Additionally, Henke assumed that $\mathrm{X}_{\mathrm{s}} / \mathrm{L} \geq 1$ would be true for the worst-case design impact load in a ship's life. This may not be the case for a sandwich hull. For a given uniform design load, a steel panel is usually thinner and denser than an equivalent sandwich panel of the same size. The sandwich panel typically has a higher natural frequency $\mathrm{F}_{0}$. The condition $\mathrm{X}_{\mathrm{s}} / \mathrm{L} \geq 1$ thus requires a higher pulse velocity for the sandwich panel, which may not be realistic or achievable. For illustration, consider the square panel used above. $\mathrm{X}_{\mathrm{s}} / \mathrm{L} \geq 1$ corresponds to a pulse front velocity greater than $720 \mathrm{ft} / \mathrm{s}(219 \mathrm{~m} / \mathrm{s})$, which is hardly ever achieved under actual slamming conditions. Based on these findings, it is clear that the spatially constant slamming model is inadequate for sandwich panel hull design. Worst-case traveling pulse analysis is required. 


\section{Design implications}

The designer should start with a prediction of the worst expected slamming impact velocity $V_{n}$ based on statistical analysis of the vessel's expected operating conditions and service life. He should calculate a set of possible impact geometries, putting special emphasis on those where $\beta \approx \mathrm{F}_{0}$ and $\mathrm{c}_{\mathrm{p}} \approx \mathrm{F}_{0} \mathrm{~L}$. These load cases should be run through transient analysis to verify that all stresses remain within safe values (according to the Tsai-Wu failure criterion, for example). If the panel is predicted to fail under a worst-case load condition, the designer has some mitigating options.

If the sandwich panel is orthotropic, he may re-orient the panel material by $90^{\circ}$. A traveling pressure pulse excites those harmonic mode shapes that are symmetric about the panel's vertical centerline. Therefore, re-orientation of the material will cause the slam event to excite a different set of higher-order mode shapes, causing different reinforcement and cancellation results. An orthotropic material will also have different shear strength values in each plane. The combination of these effects may be advantageous. (For these reasons, it is expected that the TYCOR ${ }^{\circledR}$ G18 panel would be more resistant to slamming impact if the webs were oriented perpendicular to the keel, rather than parallel as they were modeled in this study.)

The designer may adjust the frame and stiffener arrangement in the hull to alter the panel size and shape. A smaller panel can support a higher static pressure, which might also translate into better resistance to slamming pressure. However, a smaller panel will also have a higher natural frequency $\mathrm{F}_{0}$. Changing $\mathrm{F}_{0}$ will alter the panel's dynamic response, as suggested by the normalized results plotted in Figure 5. Moreover, changing the panel size and shape will also alter the reinforcement and cancellation relationships between the first and higher-order mode shapes. The designer should be aware that a larger panel may handle a slamming load more effectively than a smaller panel by shifting the limiting pulse away from the peak response region. Another approach could be to add soft, flexible backing material to raise mass and reduce $\mathrm{F}_{0}$ without changing panel size. If these approaches prove insufficient, it may be necessary to choose a different panel material, change the hull shape, or reduce the vessel's performance specifications.

\section{Conclusions}

Sandwich composite panels behave fundamentally differently from isotropic panels. Slam-loaded sandwich panels have higher peak stresses relative to peak deflections, confirming that the slamming load distribution is not well represented by a spatially constant pulse model. Under slam loading, transverse shear is more significant than bending compared to a uniformly loaded panel. Past ship design practices used simplifying assumptions that are inadequate for sandwich panel hulls exposed to slamming impacts. It has been shown that 
Henke's 7\% error criterion for the spatially constant pulse model cannot be applied to composite sandwich panels in general. Therefore, dynamic analysis of a traveling pulse is essential for effective design.

\section{References}

[1] Lewis, R.R., Sarkani, S., \& Beach, J.E., A structural system-response approach for statistically estimating wave impact design pressures. $A S N E$ Day 2006, Arlington, Virginia, 2006.

[2] Grimsley, J.S., A comparison of prediction methods for impact pressures of high-speed light craft. B.S. thesis, Webb Institute of Naval Architecture, Glen Cove, New York, 1998.

[3] Battley, M. \& Lake, S., Designing composite structures for slamming loads. Proc. of the $2^{\text {nd }}$ High Performance Yacht Design Conference, Auckland, New Zealand, pp. 177-184, 2006.

[4] Stavovy, A.B. \& Chuang, S.L., Analytical determination of slamming pressures for high-speed vehicles in waves. Journal of Ship Research, 20(4), pp. 190-198, 1976.

[5] Downs-Honey, R., Edinger, S., \& Battley, M., Slam testing of sandwich panels. SAMPE Journal, 42(4), pp. 47-55, 2006.

[6] Garme, K. \& Rosén, A., Time-domain simulations and full-scale trials on planing craft in waves. International Shipbuilding Progress, 50(3), pp. 177-208, 2003.

[7] Allen, R.G. \& Jones, R.R., A simplified method for determining structural design-limit pressures on high performance marine vehicles. AIAA/SNAME Advanced Marine Vehicles Conference, AIAA 78-754, San Diego, California, 1978.

[8] Henke, D.J., Transient response of plates to travelling loads with application to slamming damage. International Journal of Impact Engineering, 15(6), pp. 769-784, 1994.

[9] Battley, M., Stenius, I., Breder, J., \& Edinger, S., Dynamic characterization of marine sandwich structures. $7^{\text {th }}$ International Conference on Sandwich Structures, ed. O. Thomsen, Springer Netherlands: Aalborg, Denmark, 2005.

[10] Battley, M. \& Stenius, I., Dynamically loaded marine composite structures. $14^{\text {th }}$ International Conference on Composite Materials, ed. M. Martin, San Diego, California, 2003.

[11] Battley, M. \& Svensson, D., Dynamic response of marine composites to slamming loads. $13^{\text {th }}$ International Conference on Composite Materials, ed. Y. Zhang, Beijing, 2001.

[12] Stoll, F., Day, S., Campbell, G.S., Banerjee, R., Sheppard, M., \& Lang, E.J., Advancements in engineered composite sandwich core materials. SAMPE '06, 51 ${ }^{\text {st }}$ International Symposium and Exhibition, eds. R. Lipeles \& D. Jenq, Long Beach, California, 2006. 